\title{
Stroke in young adults in Malaysia: 1 year outcome and functional status
}

\author{
${ }^{1}$ Yean Koon Chan, ${ }^{2}$ Kay Sin Tan, ${ }^{3,4}$ Lydia Abdul Latif \\ ${ }^{1}$ Department of Rehabilitation Medicine, Hospital Raja Perempuan Zainab II, Kelantan; ${ }^{2}$ Department \\ of Medicine and ${ }^{3}$ Department of Rehabilitation Medicine, Faculty of Medicine, University of Malaya, \\ Kuala Lumpur; ${ }^{4}$ ReGen Rehabilitation International Hospital, Petaling Jaya, Malaysia
}

\begin{abstract}
Background \& Objectives: Young stroke has socioeconomic implications. We aim to describe the demography and evaluate the long-term functional outcomes of young stroke survivors in Malaysia. Methods: First-ever Malaysian young stroke patients (18-50 years) from $1^{\text {st }}$ October 2016 until $30^{\text {th }}$ June 2018 were recruited from the University of Malaya Medical Centre Young Stroke Registry and other sources. Participants were interviewed in person or via telephone at one year post-stroke. Demographic information collected were age, sex, ethnicity, and education level. Results: Out of 120 eligible cases, there were 6 deaths $(5 \%)$ and 7 recurrent strokes $(5.8 \%)$ within 1 year. Seventy five patients were recruited for the study with mean assessment time at 14.8 months. Survivors are predominantly male (69.2\%), aged $\geq 41$ years old ( $73 \%$ ) with racial profile representative of the locality. Ischaemic stroke (IS) is the commonest stroke type (72\%) with majority TOAST classified as large-artery atherosclerosis and small-vessel disease. Hypertension and smoking are the leading risk factors. Greater than half are independent and returned to work (RTW); comparatively IS has better outcomes than haemorrhagic stroke (HS). Lesser educated survivors ( $\leq$ secondary school education, 56\%) are more likely to not RTW (OR 5, $\mathrm{p}=0.005$ ). There is no significant change in marital status and residence post stroke.

Conclusion: In a single centre study in Malaysia, major findings for young stroke survivors, mainly male in their $40 \mathrm{~s}$, at 1 year are case fatality of $5 \%$, stroke recurrence of $5.8 \%$, and more than half achieved independence and RTW (IS > HS) with education level influencing RTW.
\end{abstract}

Keywords: Young adult, adult, outcome, stroke, activities, daily living, return to work, Malaysia

\section{INTRODUCTION}

Worldwide young stroke incidence is on an increasing trend across different countries, but at variable rates due to biological, geographical and socioeconomical differences. ${ }^{1}$ Stroke in the young adult population presents unique rehabilitation challenges as compared to older stroke population as they are often employed, presenting with young dependents, and reliant on work income. ${ }^{2}$ In terms of prognostication and neurological recovery, young stroke patients generally fare better than their older counterparts, but living longer with residual disability has socioeconomic implications - dependency costs increases with greater disability. ${ }^{3}$ There are also indirect costs related to loss of productivity secondary to disability and mortality. Stroke survivors are less likely to work as compared to their healthy counterparts. ${ }^{4}$ In South Korea, the expected lifetime costs of stroke survivors whose stroke onset is at age 45 years is 4 - to 12 -fold more than those at age 65 years. ${ }^{5}$

In Malaysia, the incidence of ischemic stroke increased by $29.5 \%$ annually, while the incidence of haemorrhagic stroke increased by $18.7 \%$ from 2010 to 2014.6 A study conducted in Malaysia documented that $16 \%$ of the stroke population that presented to its hospital over a 15 -month period were aged 50 years and below. ${ }^{7}$ Malaysia comprises of multiracial communities of various Asian origins. Differences in stroke characteristics between various Asian populations in different countries have been documented ${ }^{8-9}$ A comparative study of young stroke survivors in Malaysia and Australia found significantly more large vessel atherosclerosis and small vessel occlusion among young Malaysians with ischaemic stroke as compared to Australia. ${ }^{10}$ Racial differences

Address correspondence to: Prof Dr Lydia Abdul Latif, Department of Rehabilitation Medicine, Faculty of Medicine, University of Malaya, 50603 Kuala Lumpur, Malaysia. Tel: +603-7967 6686, Email: Iydia@ ummc.edu.my; lydia.abdullatif@regen.rehab

Date of Submission: 30 November 2020; Date of Acceptance: 9 October 2021

https://doi.org/10.54029/2021iau 
in epidemiological studies refer to not just biological variations alone but reflect cultural and socioeconomic differences as well ${ }^{11}$, which would be useful to examine in the Malaysian context.

There is a paucity of studies in the longer term follow-up of young stroke patients in Malaysia including data on stroke recurrence and mortality. This study was designed to bridge this gap with the following objectives - to describe the local young stroke demographic profiles, and functional outcomes of young stroke survivors in Malaysia, and to determine any correlation between the demographic variability and their functional outcomes. This will serve to inform regarding the functional status of these young stroke survivors and educate local services in relation to the rehabilitation needs of this population.

\section{METHODS}

This prospective cohort study was conducted from April 2018 until May 2019. The study population comprised of young adult patients with first ever stroke during the period 01/10/2016 to 30/6/2018 registered in University of Malaya Medical Centre (UMMC). These patients were identified from the Young Stroke registry comprising of direct admission to neurology wards. In addition, patient recruitment was obtained by access to referrals to the rehabilitation team from the neurosurgical wards, via direct admission to the rehabilitation ward from other hospitals, and from the outpatient rehabilitation clinic which receive referrals from both inside and outside of UMMC.

Inclusion criteria were patients' age (18 - 50 years old), Malaysian national and diagnosis of first ever ischaemic/haemorrhagic stroke (IS/ HS). Non-Malaysian nationals were excluded because most chose to return to their country of origin post-stroke and are not available for follow-up. Other diagnoses (TIA, subarachnoid haemorrhage) were excluded as well. The patients were followed up at $\geq 1$ year post-stroke. Eligible patients were contacted, and information was obtained by interview in person or by phone for patients who were unable to come. If a patient was unable to communicate orally, a proxy was interviewed.

Demographic (age, race, sex) and clinical profile data (stroke type, risk factors) were extracted from patient's electronic medical records. Clinical investigations done allowed the IS patients to be sub-typed according to the Trial of Org 10172 in Acute Stroke Treatment (TOAST) classification. ${ }^{12}$ Patient education level was obtained via interview.
Functional outcome assessments were done according to the domains in the International Classification of Functioning, Disability and Health (ICF).${ }^{13}$ For 'activity limitation', Modified Barthel Index (MBI) ${ }^{14}$ was chosen to assess overall dependence in basic activities of daily living and mobility, whereas for 'participation restriction', the following information were gathered via interview- return to work (RTW) status, marital status change, and current residence (community dwelling vs institutionalized). For this study, 'work' refers to any paid employment including self-employment but excludes homemaker, leisure and volunteer activities.

The data was analysed using IBM SPSS Statistics Version 25. Descriptive statistics, multiple logistic regression, general linear model, Chi Square test, Spearman Correlation test and Mann Whitney U test were performed where appropriate. Statistical significance was set at $p$ value of $\leq 0.05$. This study has been approved by the Medical Research Ethics Committee of University of Malaya Medical Centre (MREC ID no: 2018129-5992).

\section{RESULTS}

A total of 145 patients were identified, in which 25 non-Malaysian nationals were excluded. (Figure 1) Out of the remaining 120 patients, 3 died in the acute phase of stroke $(2.5 \%)$; one died from massive recurrent stroke, one died from renal cancer, and another died from an uncertain cause, with overall 6 deaths (5\%) within 1 year post-stroke. 7 patients had recurrent strokes within 1 year prior to the study assessment $(5.83 \%)$, in which one was fatal. 30 patients were not contactable whilst 9 patients refused study participation. Altogether 75 patients were assessed for this study, in which 19 assessments were conducted via phone interviews. Mean time at assessment was 14.8 months post stroke (range 11-21 months). There was no significant difference in terms of the demography, stroke type and risk factors between the baseline group $(n=120)$ and those followed-up for the study $(\mathrm{n}=75)$. $($ Table 1$)$

Demographic profile of the follow-up cohort (Table 1)

Two thirds of the Malaysian young stroke patients were male $(66.7 \%)$. The ethnicity profile of the study population is as follows: Malays $(39 ; 52 \%)$, Chinese $(25 ; 32 \%)$, Indian $(10 ; 13 \%)$ and 1 Kadazan Dusun. The mean age of the participants 
Table 1: Demographic data, clinical profile and stroke subtypes of Malaysian young stroke survivors - Baseline group $(n=120)$ vs Follow-up cohort $(n=75)$

\begin{tabular}{|c|c|c|c|c|}
\hline \multirow[t]{2}{*}{ Variable } & \multirow{2}{*}{$\begin{array}{c}\begin{array}{c}\text { Baseline group } \\
(\mathbf{n = 1 2 0})\end{array} \\
\text { Number }(\mathbf{n})\end{array}$} & \multicolumn{3}{|c|}{$\begin{array}{c}\text { Follow-up } \\
\text { cohort }(n=75)\end{array}$} \\
\hline & & Percentage \% & Number (n) & Percentage \% \\
\hline \multicolumn{5}{|l|}{ Age Group } \\
\hline $18-30 y$ & 3 & 2.5 & 2 & 2.7 \\
\hline $31-40 y$ & 29 & 24.2 & 17 & 22.7 \\
\hline $41-50 y$ & 88 & 73.3 & 56 & 74.7 \\
\hline \multicolumn{5}{|l|}{ Sex } \\
\hline Male & 83 & 69.2 & 50 & 66.7 \\
\hline Female & 37 & 30.8 & 25 & 33.3 \\
\hline \multicolumn{5}{|l|}{ Ethnicity } \\
\hline Malay & 62 & 51.7 & 39 & 52.0 \\
\hline Chinese & 38 & 31.7 & 25 & 33.3 \\
\hline Indian & 19 & 15.8 & 10 & 13.3 \\
\hline Other (Kadazan Dusun) & 1 & 0.8 & 1 & 1.3 \\
\hline \multicolumn{5}{|l|}{ Education level } \\
\hline Primary education & N/A & N/A & 2 & 2.7 \\
\hline Secondary education & N/A & N/A & 40 & 53.3 \\
\hline Tertiary education & N/A & N/A & 33 & 44 \\
\hline \multicolumn{5}{|l|}{ Risk factors } \\
\hline Hypertension & 85 & 70.8 & 50 & 66.7 \\
\hline Smoking & 43 & 35.8 & 23 & 33.3 \\
\hline Diabetes mellitus & 42 & 35 & 25 & 33.3 \\
\hline Dyslipidaemia & 33 & 27.5 & 24 & 32.0 \\
\hline Cardiac embolism & 8 & 6.7 & 7 & 9.3 \\
\hline SLE & 2 & 1.7 & 2 & 2.7 \\
\hline Antiphospholipid syndrome & 2 & 1.7 & 2 & 2.7 \\
\hline Bilateral chronic DVT & 1 & 0.8 & 1 & 1.3 \\
\hline Illicit drug use & 1 & 0.8 & 0 & 0 \\
\hline Malignancy & 2 & 1.7 & 1 & 1.3 \\
\hline \multicolumn{5}{|l|}{ Stroke Type } \\
\hline Ischaemic & 86 & 71.7 & 52 & 69.3 \\
\hline \multicolumn{5}{|l|}{$\begin{array}{l}\text { TOAST classification for } \\
\text { IS }(n=52)\end{array}$} \\
\hline Large-Artery Atherosclerosis & & & 18 & 34.6 \\
\hline Cardio-embolic & & & 8 & 15.4 \\
\hline Small-vessel disease & & & 14 & 26.9 \\
\hline Other determined & & & 3 & 5.8 \\
\hline Undetermined & & & 9 & 17.3 \\
\hline Haemorrhagic & 34 & 28.3 & 23 & 30.7 \\
\hline Deaths within 1 year & $6(3$ in acute phase $)$ & $5(2.5)$ & N/A & $\mathrm{N} / \mathrm{A}$ \\
\hline $\begin{array}{l}\text { Recurrent strokes within } \\
1 \text { year }\end{array}$ & 7 & 5.8 & 5 & 6.7 \\
\hline
\end{tabular}


was 43 years old, ranging from 25 years to 51 years old on assessment. Most of them were aged 41 years and above during the stroke onset $(75 \%)$; only 2 patients were 30 years old or younger. In terms of education level, $44 \%$ had obtained tertiary education whereas the rest received secondary education or less.

Stroke subtype and risk factors of the follow-up cohort (Table 1)

Majority of the patients suffered from IS (69\%), while the remaining $31 \%$ had HS. TOAST criteria were used to subtype the ischaemic stroke research participants. Majority of them were classified under large-artery atherosclerosis (34.6\%), followed by small-vessel disease (26.9\%), cardio-embolic $(15.4 \%)$ and other determined cause $(5.8 \%)$. $17.3 \%$ were undetermined due to incomplete clinical information. There was no significant correlation between the different TOAST categories and the measured outcomes.

The most dominant risk factor noted was hypertension (67\%), followed by smoking (33\%), diabetes mellitus (33\%) and dyslipidaemia (32\%). Other young stroke risk factors identified in the population: cardiac embolism, systemic lupus erythematosus, antiphospholipid syndrome, bilateral chronic DVT, and malignancy (renal cell carcinoma, died within 10 months of stroke). 2 out of the 5 with recurrent strokes had cardioembolic cause whilst the rest had the traditional cardiovascular risk factors.

\section{Functional Outcomes (Table 2)}

Activity Limitation - MBI score. Overall, more than half $(54.7 \%)$ of the study population achieved independence (MBI score: 100) whereas almost one-third (29.3\%) were categorised under 'Slight Dependence' (MBI score: 91 - 99). There were 5 patients for 'Moderate Dependence' and 'Severe Dependence' categories each, and two patients who were totally dependent in ADL.

However, upon comparison based on types of stroke, the proportion of IS survivors who achieved independence is almost double the proportion in HS survivors (IS 64\% vs HS 35\%). There is no significant correlation between the various demographic profile and MBI score.

Participation Restriction - RTW status, marital status change, residence. 7 patients were housewives or unemployed during the onset of stroke and remained status quo post stroke. For the rest of the assessed population $(n=68), 57.4 \%$
(39) returned to work by 1 year after stroke. Again, it was noted that a larger proportion in IS survivors returned to work $(\mathrm{n}=47,64 \%)$ as compared to HS survivors $(n=21,43 \%)$. Those with secondary school education or less are 5 times more likely to not RTW as compared to their tertiary educated counterpart. (Odds ratio $5, \mathrm{p}=0.005) \mathrm{RTW}$ is positively correlated with independence in ADL. $(p \leq 0.0001)$ Almost all patients assessed maintained the same marital status post stroke except for 4 patients - two previously single patients got married, whereas another two married patients divorced after stroke. Only two patients were institutionalised (nursing home) post stroke - both were single males, with MBI scores of 13 and 45 each. Otherwise, they are community dwellers, living in family residence.

\section{DISCUSSION}

This is the first follow up study of stroke in young adults from Malaysia, an upper middle income country in South East Asia. The racial profile of the young stroke patients presented to UMMC is representative of the race distribution of the Petaling district ${ }^{15}$ where the hospital is located with no significant race predilection. Race, age, and sex did not influence the functional outcomes of young stroke survivors, except educational level, which played an important factor in RTW. This is similar to our neighbouring country, Singapore ${ }^{16}$, which reported no differences in stroke mortality and functional independence upon discharge across the 3 same racial groups. In contrast, the findings in East China ${ }^{17}$ found that young women stroke survivors are more likely to die or be more dependent at 1 year post-stroke.

Hypertension is the leading modifiable risk factor amongst the young stroke population here, followed by the other traditional cardiovascular risk factors. The outcomes are generally good for young stroke patients. However, the severity of the stroke may be fatal, as evidenced by 3 deaths $(2.5 \%)$ during the acute phase of stroke, which is consistent with other studies. ${ }^{18-19}$

Our study found that $54.7 \%$ were living independently, with the IS population generally doing better than the HS counterpart. Although the $p$ value of the difference was not statistically significant, this could be attributed to the small sample size. The FUTURE study found similar trend of independence in stroke survivors according to stroke types $-63.5 \%$ of independent IS survivors versus $50.7 \%$ independent HS survivors. ${ }^{20}$ Most of the other young stroke 
Table 2: Functional Outcomes of the Follow-up cohort - Ischaemic Stroke (IS) vs Haemorrhagic Stroke (HS)

\begin{tabular}{|c|c|c|c|c|c|c|c|}
\hline Variable & $\begin{array}{c}\text { Both } \\
\text { types of } \\
\text { stroke } \\
(n=75)\end{array}$ & & $\underset{\substack{\text { IS } \\
(n=52)}}{ }$ & & $\begin{array}{c}\text { HS } \\
(n=23)\end{array}$ & & $\begin{array}{c}p \text { value } \\
\text { of overall } \\
\text { difference } \\
\text { between IS } \\
\& \text { HS }\end{array}$ \\
\hline & $\begin{array}{l}\text { Number } \\
\text { (n) }\end{array}$ & $\begin{array}{c}\text { Percentage } \\
(\%)\end{array}$ & $\begin{array}{l}\text { Number } \\
\text { (n) }\end{array}$ & $\begin{array}{c}\text { Percentage } \\
(\%)\end{array}$ & $\begin{array}{l}\text { Number } \\
\text { (n) }\end{array}$ & $\begin{array}{c}\text { Percentage } \\
(\%)\end{array}$ & \\
\hline $\begin{array}{l}\text { MBI level of } \\
\text { independence }\end{array}$ & & & & & & & 0.131 \\
\hline $\begin{array}{l}\text { Total } \\
\text { dependence } \\
(0-20)\end{array}$ & 2 & 2.7 & 1 & 1.9 & 1 & 4.3 & \\
\hline $\begin{array}{l}\text { Severe } \\
\text { dependence } \\
(21-60)\end{array}$ & 5 & 6.7 & 3 & 5.8 & 2 & 8.7 & \\
\hline $\begin{array}{l}\text { Moderate } \\
\text { dependence } \\
(61-90)\end{array}$ & 5 & 6.7 & 4 & 7.7 & 1 & 4.3 & \\
\hline $\begin{array}{l}\text { Slight } \\
\text { dependence } \\
(91-99)\end{array}$ & 22 & 29.3 & 11 & 21.2 & 11 & 47.8 & \\
\hline $\begin{array}{l}\text { Independence } \\
(100)\end{array}$ & 41 & 54.7 & 33 & 63.5 & 8 & 34.8 & \\
\hline RTW status & & & & & & & 0.106 \\
\hline $\begin{array}{l}\text { Housewife/ } \\
\text { previously } \\
\text { unemployed }\end{array}$ & 7 & 9.3 & 5 & 9.6 & 2 & 8.7 & \\
\hline $\begin{array}{l}\text { Returned to } \\
\text { work }\end{array}$ & 39 & 52 & 30 & 57.7 & 9 & 39.1 & \\
\hline $\begin{array}{l}\text { Did not } \\
\text { return to work }\end{array}$ & 29 & 38.7 & 17 & 32.7 & 12 & 52.2 & \\
\hline $\begin{array}{l}\text { Marital status } \\
\text { post stroke }\end{array}$ & & & & & & & 0.182 \\
\hline Unchanged & 71 & 94.6 & 50 & 96.2 & 21 & 91.3 & \\
\hline Got married & 2 & 2.7 & 2 & 3.8 & 0 & 0 & \\
\hline Got divorced & 2 & 2.7 & 0 & 0 & 2 & 8.7 & \\
\hline $\begin{array}{l}\text { Residence } \\
\text { post stroke }\end{array}$ & & & & & & & 0.548 \\
\hline $\begin{array}{l}\text { Community } \\
\text { dwelling }\end{array}$ & 73 & 97.3 & 51 & 98.1 & 22 & 95.7 & \\
\hline $\begin{array}{l}\text { Institution } \\
\text { (nursing } \\
\text { home) }\end{array}$ & 2 & 2.7 & 1 & 1.9 & 1 & 4.3 & \\
\hline
\end{tabular}




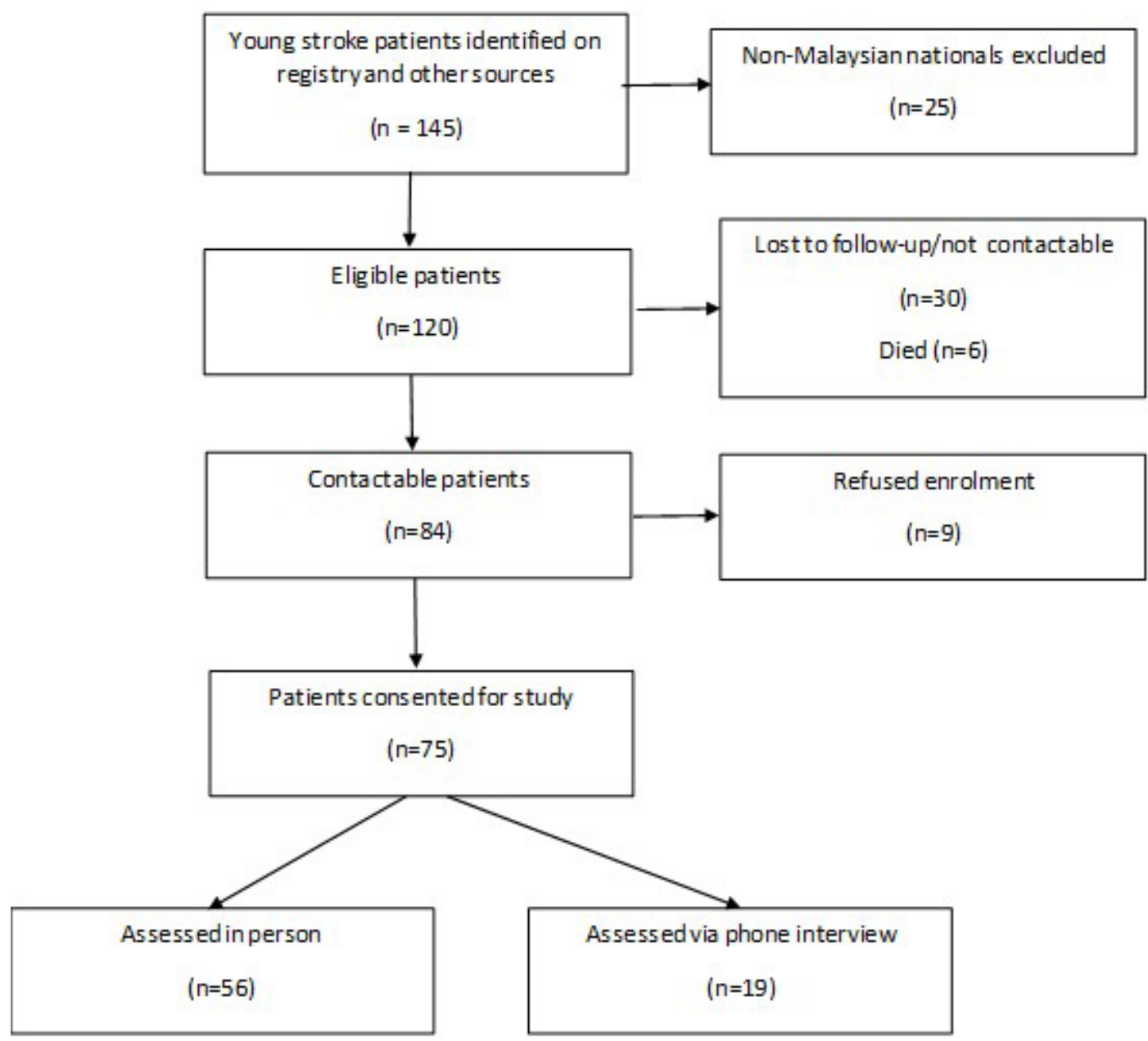

studies focused on ischaemic stroke (which may include transient ischaemic attack in their study population) reported higher figures ranging from $63.5 \%-94 \% .21-25$ Our results show that greater independence in ADL is correlated with more successful RTW, similar to the findings by Edwards et al. ${ }^{26}$

Generally half of the young stroke survivors returned to work within one year post-stroke which is comparable to the findings of a systematic review on RTW rate among young stroke survivors - RTW increased with increasing time median frequency, i.e. $41 \%$ between 0 and 6 months, $53 \%$ at 1 year, $56 \%$ at 1.5 years to $66 \%$ between 2 and 4 years post-stroke. ${ }^{26}$ The higher proportion of haemorrhagic stroke survivors not returning to work as compared to ischaemic stroke survivors is consistent with previous studies, ${ }^{27-29}$ despite the $p$ value being not statistically significant as this could be due to the small sample size.
Lower educational level is an independent predictor of RTW during the early post-stroke years in Sweden and Korea. ${ }^{30-32}$ The increased odds of those with lesser education not returning to work implies types of occupation affected (white vs blue collar) and the correlating job demands and possible job modifications. A physicalfocused occupation may not have much room for modification to accommodate the stroke survivor's abilities. Their education level may also be an indirect marker of underlying socioeconomic status which influences their access to outpatient rehabilitation services ${ }^{27,30,33}$ Sickness benefits may also influence the RTW decision of the stroke survivor. ${ }^{34}$

Unlike the findings in other studies which reported divorce ${ }^{2,21,35}$, there was no significant change in the marital status of the Malaysian young stroke survivors. Almost all the young stroke survivors lived with their family in the 
community. The two participants in our study that were institutionalised $(2.7 \%)$ were single males with moderate to total dependency. Teasell et $a l^{2}$ found $4.8 \%$ of young stroke survivors were institutionalised at 3-months post-discharge from rehabilitation facility. The lesser rate here in Malaysia could be attributed to the Asian cultural factor, in which family is encouraged to be caregivers, as compared to our Caucasian counterparts. ${ }^{36}$

\section{Strength and limitation of this study}

To our knowledge, this is the only follow up study of young stroke patients in Malaysia. However, there are some study limitations identified. The data collected for this study is from a single centre in an urban population with a small sample size. A significant portion of the young stroke survivors were lost to follow-up or refused study participation, whose current functional status are unknown. Nevertheless, it is still a useful insight into the young stroke population in the locality.

In conclusion, stroke in young adults has serious impact on the individual, family and the community. Majority of the young stroke survivors are males in their $40 \mathrm{~s}$. There is a $2.5 \%$ chance of acute mortality with overall 5\% mortality and 6\% chance of recurrence within one year post stroke. The traditional cardiovascular risk factors remain the main culprits for young stroke; however, other risk factors unique to young stroke population such as cardiac and autoimmune diseases need to be addressed as well.

Our study shows that slightly more than half of our young stroke survivors achieve independence and returned to work. Those with secondary school education or less are 5 times more likely to not return to work as compared to those with tertiary education.

Early appropriate rehabilitation intervention may reduce disability, thus reducing the cost of dependency, improve independence and increase likelihood of return to work.

\section{ACKNOWLEDGEMENTS}

We thank Associate Prof Dr. Karuthan Chinna from the Department of Social and Preventive Medicine in the Faculty of Medicine, University of Malaya, for his assistance with the statistical analyses. Data collection for UMMC Young Stroke registry was supported in part by funds from UMMC Clinical Investigations Centre Neurovascular grant.

\section{DISCLOSURES}

Conflicts of interest: None

\section{REFERENCES}

1. Ekker MS, Boot EM, Singhal AB, et al. Epidemiology, aetiology, and management of ischaemic stroke in young adults. Lancet Neurol 2018; 17:790-801.

2. Teasell RW, McRae R, Finestone HM. Social issues in the rehabilitation of younger stroke patients. Arch Phys Med Rehabil 2000; 81: 205-9.

3. O'Connor RJ, Beden R, Pilling A, Chamberlain MA. What reductions in dependency costs result from treatment in an inpatient neurological rehabilitation unit for people with stroke? Clin Med 2011; 11: 40-3.

4. Schnitzler A, Jourdan C, Josseran L, Azouvi P, Jacob L, Genêt F. Participation in work and leisure activities after stroke: A national study. Ann Phys Rehabil Med 2019; 62: 351-5.

5. Kang HY, Lim SJ, Suh HS, Liew D. Estimating the lifetime economic burden of stroke according to the age of onset in South Korea: a cost of illness study. BMC Public Health 2011; 11:646.

6. Aziz ZA, Lee YY, Ngah BA, et al. Acute stroke registry Malaysia, 2010-2014: results from the National Neurology Registry. J Stroke Cerebrovasc Dis 2015; 24: 2701-9.

7. Then LYY, Wong CK, Tan YY, Loo YP, Sim SH. Epidemiology and etiology of young stroke: The perpetual challenge. J Neurol Sci 2017; 381: 1111.

8. Khan NA, Quan H, Hill MD, et al. Risk factors, quality of care and prognosis in South Asian, East Asian and White patients with stroke. BMC Neurol 2013; 13: 74

9. Akhtar N, Salam A, Kamran S, et al. Ethnic variation in acute cerebrovascular disease: analysis from the Qatar stroke registry. Eur Stroke J 2016; 1: 231-41.

10. Tan KS, Tan CT, Churilov L, Mackay M, Donnan GA. Ischaemic stroke in young adults: A comparative study between Malaysia and Australia. Neurol Asia 2010; 15: 1-9.

11. Lin SS, Kelsey JL. Use of race and ethnicity in epidemiologic research: concepts, methodological issues, and suggestions for research. Epidemiol Rev 2000; 22: 187-202.

12. Adams Jr HP, Bendixen BH, Kappelle LJ, et al. Classification of subtype of acute ischemic stroke. Definitions for use in a multicenter clinical trial. Stroke 1993; 2:35-41.

13. World Health Organization. International classification of functioning, disability and health: ICF. World Health Organization. https://apps.who.int/iris/ handle/10665/42407.2001. Access date: 20 October 2019.

14. Shah S, Vanclay F, Cooper B. Improving the sensitivity of the Barthel Index for stroke rehabilitation. J Clin Epidemiol 1989; 42:703-9.

15. Department of Statistics, Malaysia. Population and demographic characteristics 2010.

16. Sharma VK, Tsivgoulis G, Teoh HL, Ong BK, Chan BP. Stroke risk factors and outcomes among various Asian ethnic groups in Singapore. J Stroke Cerebrovas Dis 2012; 21:299-304. 
17. Geng C, Lin Y, Tang Q, et al. Sex differences in clinical characteristics and 1-year outcomes of young ischemic stroke patients in East China. Ther Clin Risk Manag 2019; 15: 33-8.

18. Ekker MS, Verhoeven JI, Vaartjes I, Jolink WMT, Klijn CJM, de Leeuw FE. Association of stroke among adults aged 18 to 49 years with long-term mortality. JAMA 2019; 321: 2113-23.

19. Dash D, Bhashin A, Kumar Pandit A, et al. Risk factors and etiologies of ischemic strokes in young patients: a tertiary hospital study in north India. $J$ Stroke 2014; 16:173-7.

20. Synhaeve NE, Arntz RM, Maaijwee NA, et al. Poor long-term functional outcome after stroke among adults aged 18 to 50 years: Follow-Up of Transient Ischemic Attack and Stroke Patients and Unelucidated Risk Factor Evaluation (FUTURE) study. Stroke 2014; 45: 1157-60.

21. Leys D, Bandu L, Henon H, et al. Clinical outcome in 287 consecutive young adults ( 15 to 43 years) with ischemic stroke. Neurology 2002; 59:26-33.

22. Musolino R, La Spina P, Granata A, et al. Ischaemic stroke in young people: a prospective and long-term follow-up study. Cerebrovasc Dis 2003; 15: 121-8.

23. Naess H, Nyland HI, Thomassen L, Aarseth J, Myhr $\mathrm{KM}$. Long-term outcome of cerebral infarction in young adults. Acta Neurol Scand 2004; 110: 107-12.

24. Spengos K, Vemmos K. Risk factors, etiology, and outcome of first-ever ischemic stroke in young adults aged 15 to $45-$ the Athens young stroke registry. Eur J Neurol 2010; 17: 1358-64.

25. Hoffmann, M. Stroke in the young in South Africa - an analysis of 320 patients. S Afr Med J 2000; 90 : 1226-37.

26. Edwards JD, Kapoor A, Linkewich E, Swartz RH. Return to work after young stroke: a systematic review. Int J Stroke 2018;13(3):243-56.

27. Hannerz H, Pedersen BH, Poulsen OM, Humle $\mathrm{F}$, Andersen LL. A nationwide prospective cohort study on return to gainful occupation after stroke in Denmark 1996-2006. BMJ Open 2011; 1: e000180.

28. Maaijwee NA, Rutten-Jacobs LC, Arntz RM, et al. Long-term increased risk of unemployment after young stroke: a long-term follow-up study. Neurology 2014; 83: 1132-8.

29. Catalina-Romero C, Ruilope LM, Sánchez-Chaparro MA, et al. Factors influencing return-to-work after cerebrovascular disease: the importance of previous cardiovascular risk. Eur J Preventive Cardiol 2015; 22: $1220-7$.

30. Trygged S, Ahacic K, Kåreholt I. Income and education as predictors of return to working life among younger stroke patients. BMC Public Health 2011; 11: 742.

31. Westerlind E, Persson HC, Eriksson M, Norrving B, Sunnerhagen KS. Return to work after stroke: A Swedish nationwide registry-based study. Acta Neurol Scand 2020 141:56-64.

32. Chang WH, Sohn MK, Lee J, et al. Return to work after stroke: The KOSCO Study. J Rehabil Med 2016; 48:273-9.

33. Aarnio K, Rodríguez-Pardo J, Siegerink B, et al. Return to work after ischemic stroke in young adults:
A registry-based follow-up study. Neurology 2018; 91: e1909-e1917

34. Saeki, S. Disability management after stroke: its medical aspects for workplace accommodation. Disabil Rehabil 2000; 22: 578-82.

35. Daniel K, Wolfe CD, Busch MA, McKevitt C. What are the social consequences of stroke for workingaged adults? A systematic review. Stroke 2009; 40: e431-e440.

36. Pharr JR, Dodge Francis C, Terry C, Clark MC. Culture, caregiving, and health: exploring the influence of culture on family caregiver experiences. ISRN Public Health 2014; Article ID 689826. 